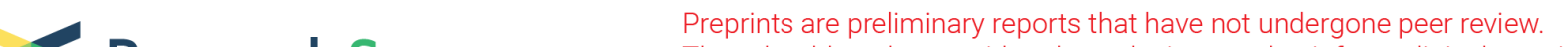 $\begin{array}{ll}\text { Research Square } & \begin{array}{l}\text { They should not be considered conclusive, used to inform clinical practice, } \\ \text { or referenced by the media as validated information. }\end{array}\end{array}$
}

\section{Upstream Region of OprD Mutations in Imipenem- Resistant and Imipenem-Sensitive Pseudomonas Aeruginosa Isolates}

\section{Masoumeh Kiani}

Shahid Sadoughi University of Medical Sciences and Health Services Yazd Research and Clinical Centre for Infertility

\section{Akram Astani}

Shahid Sadoughi University of Medical Sciences and Health Services Yazd Research and Clinical Centre for Infertility

\section{Hamed Afkhami}

Shahed University Faculty of Medical Sciences

Mansoor Khaledi

Shahed University Faculty of Medical Sciences

\section{Javad Fathi}

Shiraz University of Medical Sciences

\section{soodabeh Rostami}

Isfahan University of Medical Sciences

\section{Mohadeseh Zarei}

Shahid Sadoughi University of Medical Sciences and Health Services Yazd Research and Clinical Centre for Infertility

Hengameh Zandi ( $\sim$ h.a.university.ac@gmail.com )

Shahid Sadoughi University of Medical Sciences and Health Services

\section{Research article}

Keywords: P. aeruginosa, Antimicrobial resistance, oprD, upstream, imipenem, promoter

Posted Date: July 7th, 2020

DOI: https://doi.org/10.21203/rs.3.rs-31335/v1

License: (c) (i) This work is licensed under a Creative Commons Attribution 4.0 International License. Read Full License 


\section{Abstract}

Background: The current study was aimed to investigate the prevalence of the mutations of the oprD gene among imipenem-resistant and -sensitive Pseudomonas aeruginosa isolated from educational hospitals in Yazd, Iran.

Methods: In this study, 90 P. aeruginosa isolates were collected from different clinical samples and transferred to the Department of Microbiology, Shahid Sadoghi University of Medical Science, during 2015 to 2016. All isolates were identified by the conventional biochemical tests and antibiotic resistance was determined using disk diffusion method. E. test was performed to determine the minimum inhibitory concentrations (MIC) of imipenem. The mutations of upstream of the oprD coding region and its promoters and 54 primary nucleotide of this gene were recognized by the amplification of this region and subsequently sequenced.

Results: Seventy $(77.7 \%)$ of isolates had $\mathrm{MIC} \geq 16$ and were resistant to imipenem. The results showed that the rate of resistance to imipenem is increasing. Mutations of the upstream of the oprD gene and its promoters were seen in $25(86.2 \%)$ of isolates and 4 strains had no mutation. All of the imipenemresistant isolates had mutations. One isolate had a base substitution $A \rightarrow C$ at nt 25 in coding region and this isolate had a point mutation leading to an amino acid change at positions $9(\mathrm{I} \rightarrow \mathrm{L})$.

Conclusion: The results showed that imipenem resistance is increasing in $P$. aeruginosa, also indicated that the point mutations were the most common cause of the inactivation of upstream of the oprD coding region among $P$. aeruginosa isolates, it seems this mechanism is effective in resistance of isolates to imipenem.

\section{Background}

Pseudomonas aeruginosa is an opportunistic pathogen that causes a variety of infections in immunocompromised patients. In recent years, Antibiotic resistance of $P$. aeruginosa is increasing and the selection of suitable treatments has become difficult and associated with increased morbidity and mortality $(1,2)$. Carbapenems, mainly imipenem and meropenem, are important and useful antibiotics for the treatment of infections due to multidrug-resistant Pseudomonas. Carbapenems are a class of $\beta$ lactam antibiotics with good antimicrobial activity against $P$. aeruginosa $(3,4)$. Carbapenem resistance of $P$. aeruginosa is mainly due to a combination of different factors, including low outer membrane permeability and mutations in the genes encoding $\mathrm{OprD}$, the production of the AmpC bate-lactamases, overproduction of efflux systems, and producing Carbapenemase (5-7). However, among these mechanisms, the Loss or mutation of outer membrane OprD porin and promoter of this gene appears to be the most common mechanisms of intrinsic resistance to imipenem, and a lesser extent to meropenem. This mechanism causes blocking of the entrance of carbapenems particularly imipenem into a bacterium $(8,9)$. OprD-mediated resistance occurs as a result of decreased transcriptional expression of oprD and/or loss of function mutations that disrupt protein activity. $O p r D$, an outer membrane porin, is a 
semipermeable barrier and substrate-specific penetrable protein consisting of 443 amino acids that allows the diffusion of basic amino acids and carbapenems typically imipenem into the cell $(6,10)$. OprD mediated resistance occurs as a result of decreased expression of oprD or mutations that it hampered protein activity. Specific mechanisms resulting in decreased transcriptional expression of oprD include (i) disruption of the oprD promoter, (ii) premature termination of oprD transcription, (iii) co-regulation with trace metal resistance mechanisms, (iv) salicylate-mediated reduction, and (v) decreased transcriptional expression via co-regulation with the multidrug efflux pump encoded by mexEF-oprN (8). The typed of mutations in the oprD gene and upstream region and promoter of oprD gene are various such as nucleotide deletions, insertions and point mutations that have been recognized to be the major mechanisms leading to inactivation of the oprD coding region and promoter from imipenem-resistant isolates of P.aeruginosa $(5,11)$. Transcription of oprD in P. aeruginosa PA01 initiates with equal frequencies from two start sites, located 23 bases (SS1) and 71 bases (SS2) upstream of the structural gene. The previous investigate, have observed two or three types of imipenem-resistance mutants in clinical isolates. The major type involves deletion and point mutations (12). These well-known alterations are commonly reported, include point mutations or insertion sequences (ISs) inactivating the in resistance to imipenem, especially in Iran. Therefore, the aim of this study was to evaluate the prevalence of mutations in upstream of the oprD coding region and its promoters in imipenem resistant and sensitive Pseudomonas aeruginosa isolated from educational hospitals.

\section{Methods}

\subsection{Bacterial Isolates}

In a descriptive study, 90 isolates of $P$. aeruginosa were collected from June 2015 to April 2016at Teaching Hospitals of Shahid Sadoghi University of Medical Science, Yazd, Iran. These isolates were originated from different clinical specimens of hospitalized patients, including blood, burn wounds, urine, lungs, etc. The study was approved by Shahid Sadoghi University of Medical Science, Yazd, Iran and ethical code was IR.SSU.REC.1391.24.

\subsection{Antimicrobial Susceptibility Testing}

After transferring the plate containing Gram-negative rod colonies to the Laboratory of Microbiology, suspected colonies were identified by Gram staining and conventional biochemical tests such as catalase, oxidase, and growth in $42{ }^{\circ} \mathrm{C}$, Oxidative/fermentative test, and differential media such as TSI (Merck, Germany). Isolate identified as $P$. aeruginosa were stored at $70^{\circ} \mathrm{C}$ in trypticase soy broth (Merck) supplemented with $20^{\circ} \mathrm{C}$ glycerol unit.

\subsection{Minimum Inhibitory Concentration and Phenotypic Confirmatory Tests}

Antibiotic susceptibility testing of the isolates was performed using the disk diffusion method (KirbyBauer) according to Clinical and Laboratory Standard Institute guideline (CLSI, 2014) using MuellerHinton agar (Merck, Germany) and Imipenem, meropenem, ertapenem, ciprofloxacin, ceftazidime, 
Cefepime, ceftriaxone, gentamicin, and tobramycin (MAST, UK). P. aeruginosa ATCC27853 was used as quality control. The Minimum Inhibitory Concentration (MIC) of imipenem was performed by E. test strips (Liofilchem, Italy) as described in the manufacturer's instructions. MIC breakpoint was defined according to CLSI guideline (CLSI, 2014).

\subsection{DNA extraction}

DNA extraction was performed using by salting out method and was stored at $-20^{\circ} \mathrm{C}$ until further use (18).

\subsection{PCR for detection of $o p r D$ gene}

The occurrence of oprD gene was screened in all isolates by PCR. primers were developed for each gene using Primer 3. The primers used for DNA amplification, as follows: 5'- AGACATGCCGTGGATACAAA -3' for the forward and 5'-AGTGCTACCTGCGGAAACC -3 ' for the reverse primers. The final optimized PCR reaction consisted of $0.5 \mu \mathrm{l} \mathrm{MgCl} 2(100 \mathrm{mM}), 0.5 \mu \mathrm{dNTP}(10 \mathrm{mM}), 0.2 \mu \mathrm{l}$ ( 1 unit) Taq DNA polymerase (Cinnagen, Iran), $1 \mu$ of each primer (10 pmol) (Alpha DNA, Canada), $2.5 \mu$ PCR buffer ( $10 \mathrm{X}$ ), and $0.5 \mu \mathrm{l}$ of DNA template $(100 \mu \mathrm{g} / \mathrm{ml})$ in a total volume of $25 \mu \mathrm{l}$ with double distilled water. DNA amplification was carried out with a thermocycler (Quanta Biotech, England), PCR amplification was performed as follows: one cycle at $95^{\circ} \mathrm{C}$ for 300 seconds, then 30 cycles at $95^{\circ} \mathrm{C}$ for $45 \mathrm{Sec}, 56^{\circ} \mathrm{C}$ for $45 \mathrm{Sec}$, and 72 ${ }^{\circ} \mathrm{C}$ for $60 \mathrm{Sec}$ and a final extension at $72^{\circ} \mathrm{C}$ for $10 \mathrm{~min}$ using an initial denaturation step for $5 \mathrm{~min}$ at $94^{\circ} \mathrm{C}$ (one cycle), followed by 35 cycles of $1 \mathrm{~min}$ at $94^{\circ} \mathrm{C}, 1 \mathrm{~min}$ at $50^{\circ} \mathrm{C}$ and $1 \mathrm{~min}$ at $72^{\circ} \mathrm{C}$. The amplified products were analyzed by $1.5 \%(\mathrm{w} / \mathrm{w})$ agarose gel electrophoresis and were visualized on an ultraviolet illumination after staining with ethidium bromide. A mutation in the promotor and upstream coding region of OprD gene (Table 4) was identified by DNA sequencing.

\subsection{DNA sequencing and analyses of sequence data}

According to imipenem MIC results, 29 isolates were selected randomly for evaluation of the mutations. For DNA sequencing, upstream regions and fifty four (54) primary nucleotide of oprD gene were sequenced. The sequences results were aligned and analyzed using MEGA 6 software and CLUSTAL W2, Vector NTI Advance version9. 0.0 software (InforMax; Invitrogen). Protein alignments were carried out using. ClustalW2 (http://www.ebi.ac.uk/Tools/msa/clustalw2/). In every case, both the nucleotide and the amino acid sequences were compared between the clinical isolates, the PAO1 reference (strain NC 002516.2 and gb AE004091.2)

\subsection{Statistical analysis}

The data were analyzed using the Statistical Program for Social Sciences version 18. (SPSS Version. 18 IBM, Chicago, IL, USA). For the analysis of data, chi-square tests were employed to calculate the P-value. Statistical significance and levels were set at $P<0.05$.

\section{Results}




\subsection{Bacterial isolates}

Of 90 P. aeruginosa isolates, $38.9 \%, 20 \%$ and $13.3 \%$ of them were isolated from burn wounds, urine, and wound specimens respectively. The Sources of P. aeruginosa isolates according to the hospital ward include Burn (43.3\%), ICU (22.2\%), Internal (15.6\%), Surgery (11.1\%), and other wards (7.7 \%).

\subsection{Antibiotic resistance patterns}

The frequency of resistance to carbapenems was as follows: imipenem $48.9 \%$, meropenem $56.6 \%$ and Ertapenem $52.5 \%$. The results of antimicrobial susceptibility testing using the disk diffusion method are shown in table 1. The results of the MIC of Imipenem by an E-test method are shown in table 2.

\subsection{PCR and sequencing}

The oprD gene and upstream regions was amplified by PCR. The electrophoresis agarose gel was performing on PCR products was shown in Figure. The size of the amplified fragment is 570 base pairs. As shown in Figure1. The oprD gene was sequenced, including the promoter and

upstream regions including Shine-Dalgarno (GGAG; nucleotides -12 to -9), -10 (TAAGTT; nucleotides -84 to -79), and -35 (TCGCCA; nucleotides - 107 to -102) sequences.

Of 30 isolates selected for sequencing, $25(86.2 \%)$ of isolates had mutations that all $(100 \%)$ of them were resistant to imipenem. Percent of mutations in resistant and sensitive isolates revealed in Table 3 . There was a significant relationship $(\mathrm{P}<0.05)$ between mutations of upstream of the oprD coding region and MIC of imipenem.

The frequency of mutations in the upstream region of $o p r D$ gene based on specimens was as follows: Burn $57.69 \%$, Urine $19.23 \%$, and other specimens $23.07 \%$. Although the most mutations were seen in $P$. aeruginosa isolated from burn specimens and burn ward. The Statistical analysis didn't find any significant correlation between age and sex of the patient. Based on the observed mutations, none of the strains had no mutation in Shine-Dalgarno (GGAG; nucleotides - 12 to -9), -10 (TAAGTT; nucleotides -84 to $-79)$, and -35 (TCGCCA; nucleotides -107 to -102) sequences and $25(86.2 \%)$ strains have mutations in the upstream of the structural gene. Six isolates have point mutations in promoter: Five isolates had $T \rightarrow C$ base substitution at nt -90 and One isolate had a base substitution $G \rightarrow C$ at nt -120 , Also One isolate had a base substitution $\mathrm{A} \rightarrow \mathrm{C}$ at $\mathrm{nt} 25$ in coding region and this isolate had a point mutation leading to an amino acid change at positions $9(\mathrm{I} \rightarrow \mathrm{L})$. The rest of results sequencing of upstream regions and promoter regions are shown in table 4.

\section{Discussion}

In medicine, the treatment of community-acquired infections and nosocomial infections caused by P.aeruginosa is important. Carbapenem is effective against infectious diseases caused by $P$. aeruginosa. However, carbapenem-resistant $P$. aeruginosa strains are emerging worldwide, and the rate of resistance 
in most countries ranges from 10 to $50 \%$ (13). In the present study, the prevalence of imipenem resistance in bacteremic $P$. aeruginosa was $48.9 \%$, and the rate of resistance of $P$. aeruginosa to imipenem was $5.5 \%$ to $62.5 \%$ in other studies (14-22). According to studies of antibiotic resistance in different parts of the world and the result of the present study; it can be concluded that resistance rates in $P$. aeruginosa isolates were higher than previous reports, which can be due to a combination of different factors such as the inconsiderate use or the previous use of antibiotics, differences in the type of sample, and the geographical region and care of patients in hospitals and difference in mechanism of resistance. Since the carbapenem are commonly used in the treatment and mutations in oprD gene and promoter in upstream regions are the most current reason against resistance to these antibiotics, so identify and assess the prevalence of these mutations in the bacteria population can be very effective in a susceptibility bacteria population. The mutational inactivation of the oprD gene and disruption in promoter represents the major cause of OprD loss in $P$. aeruginosa strains. In our study alterations were observed in resistant isolates. Mutations of the upstream region oprD were seen in all (25) imipenemresistant isolates. Mutations in SS1 and SS2 were point mutations. The most frequent causes of oprD mutational inactivation were point mutations leading to alterations the amino acid profile. In this study, alterations observed, mainly lead to an increase in the MIC and resistance to imipenem. One isolate had a base substitution $A \rightarrow C$ at $n t 25$ in coding region and this isolate had a point mutation leading to an amino acid change at positions $9(\mathrm{I} \rightarrow \mathrm{L})$. Also, the insertion of one base was seen in five isolates and the insertion of tree nucleotide were observed in one isolate. In a study performed by Fournier et al (23). Mutations of the oprD gene were seen in $86.2 \%$ of imipenem-resistant isolates. A similar study conducted by Alain A et al (3). 77 (77\%) of isolates had mutations and mutations were observed in both sensitive and resistant isolates. The most isolates showed point mutations and deletion mutations. Reports had done, shows that mutation and inactivation or loss of an oprD gene, disruption in promoter and upstream region of oprD gene in $P$. aeruginosa strains are the major mechanisms that cause resistance to imipenem. This result was in accordance with previous investigation of clinical isolates of $P$. aeruginosa. In a study performed by Aki Hirabayashi et al (24). There was a direct relationship between the alteration or loss of oprD and the increase in MIC, for imipenem but not meropenem and other carbapenems $(3,9$, 11). In a study conducted by Yumiko Sanbongi et al (25). The highest mutation was a frame-shift mutation or deletion mutation. Gutiérrez et al (11). Have reported different mutations in the oprD gene, the most frequent mutations were frameshift mutations produced by one nucleotide insertions or deletions and point mutations leading to the creation of a premature stop. In a study performed by EL Amin et al (8). Mutation of inactivation, including the insertion or deletion of one and two or more nucleotides and insertion sequences (IS). In investigating Performed by Wolter DJ et al (26). PCR and sequence analysis revealed an interpolation of a large fragment in the oprD gene were known as IS elements that are not observed in this study. Jilu Shen et al (9). Reported $96.5 \%$ (136/141) of the resistant isolates showed deletions or multi mutations that were driven loss or insertion of the oprD-encoding gene, 34 strains had a large deletion in the OprD gene, 6 isolates had IS, and 4 strains had no mutation and showed a normal OprD2 gene. In this study, the insertion of one base was seen in five isolates and four isolates had no mutation.Yoneyama et al (1). Reported the association of a large deletion encompassing the putative promoter and initiation codon that prevented transcription of oprD and deletion mutations were observed, 
including deletion an $11 \mathrm{bp}$ and a large deletion from nucleotides 519-685. Qinghui Sun et al (27). Have reported an insertion sequence element (ISRP10) that causes to disrupt the oprD gene and seen in $96 \%$ of imipenem-resistant Pseudomonas aeruginosa isolates. In a study performed by Yingjun Yan et al (28). The result of the analysis, indicating that the 4-bp insertion in the oprD gene resulted in a frameshift in the OprD gene and imipenem resistance. A different study conducted by Hussein Chalhoub a Sequencing showed no mutation in the promoter region of the gene, but several in the coding region oprD promoter disruptions have occurred as a result of deletions or insertions within the upstream region of oprD (29).

\section{Results}

The results of this study showed, increase the resistance of $P$. aeruginosa to carbapenem family antibiotics such as imipenem. Mutations caused by substitution nucleotide and deletions or insertions within the upstream region of oprD and in the oprD structural gene can lead to increases of the MICs of imipenem. Usage of imipenem should be controlled to prevent pan-drug resistant. In our country, there is little information about the contribution of different mechanisms to carbapenem resistance in these isolates, especially about oprD mutations and upstream region of and promotores mutations in imipenem-resistance isolates. Awareness of resistant mechanisms in Paeruginosa isolates could help to regulation infection control strategies and enhances the efficacy of imipenem for treatment of infections due to this bacteria. Thus, there is a need to focus on intrinsic resistance mechanisms, especially Porin alteration which also confers significant imipenem resistance, also suggests in future other mechanisms are evaluated and investigates in other isolates and in other places.

\section{Declarations}

\section{Ethics approval and consent to participate}

The study was approved by Shahid Sadoghi University of Medical Science, Yazd, Iran and ethical code was IR.SSU.REC.1391.24.In this study, the patient and human samples were not examined directly and the bacterial samples were collected from the Teaching Hospitals of Shahid Sadoghi University of Medical Science, Yazd, Iran.

\section{Consent for publication}

There is no limit to the publication.

\section{Availability of data and materials}

All data generated or analyzed during this study are included in this published article.

\section{Competing interests}

We declare that we have no conflict of interest. 


\section{Funding}

Not applicable

\section{Author's contributions}

HZ: Project development, Management and Manuscript writing. MK: Project development; Management and Manuscript writing. AA: Data collection and Manuscript writing. HA: Data collection and Data analysis. MKH: Manuscript writing and Data analysis. JF: Manuscript writing, Manuscript editing and Data analysis. SR: Manuscript writing and Data analysis. MZ: Data collection and Manuscript writing. All Authors read and approved the manuscript.

\section{Acknowledgements}

This research project was financially supported by Yazd University of Medical Sciences. The authors wish to thank Yazd University of Medical Sciences for providing this grant to finance this research.

\section{Author Information}

${ }^{1}$ Department of Microbiology, Faculty of Medicine, Shahid-Sadoughi University of Medical Sciences, Yazd, Iran

${ }^{2}$ Phd Student of Medical Bacteriology, Department of Medical Microbiology, Faculty of Medicine, Shahed University of Medical Science, Tehran, Iran

${ }^{3}$ Department of Bacteriology and Virology, School of Medicine, Shiraz University of Medical Sciences, Shiraz, Iran

${ }^{4}$ Nosocomial infections Research Center, Isfahan University of Medical Sciences, Isfahan, Iran

\section{References}

1. Yoneyama $\mathrm{H}, \mathrm{Nakae} \mathrm{T}$. Mechanism of efficient elimination of protein D2 in outer membrane of imipenem-resistant Pseudomonas aeruginosa. Antimicrob Agents Chemother. 1993;37(11):2385-90.

2. Riera E, Cabot G, Mulet X, García-Castillo M, del Campo R, Juan C, Cantón R, Oliver A. Pseudomonas aeruginosa carbapenem resistance mechanisms in Spain: impact on the activity of imipenem, meropenem and doripenem. Journal of antimicrobial chemotherapy. 2011;66(9):2022-7.

3. Ocampo-Sosa AA, Cabot G, Rodríguez C, Roman E, Tubau F, Macia MD, Moya B, Zamorano L, Suárez C, Peña C. Alterations of OprD in carbapenem-intermediate and-susceptible strains of Pseudomonas aeruginosa isolated from bacteremia in a Spanish multicenter study. Antimicrobial agents and chemotherapy. 2012:AAC. 05451-11.

4. Lister PD, Wolter DJ, Hanson ND. Antibacterial-resistant Pseudomonas aeruginosa: clinical impact and complex regulation of chromosomally encoded resistance mechanisms. Clin Microbiol Rev. 
2009;22(4):582-610.

5. Pirnay JP, Vos DD, Mossialos D, Vanderkelen A, Cornelis P, Zizi M. Analysis of the Pseudomonas aeruginosa oprD gene from clinical and environmental isolates. Environ Microbiol. 2002;4(12):87282.

6. Hancock RE, Brinkman FS. Function of Pseudomonas porins in uptake and efflux. Annual Reviews in Microbiology. 2002;56(1):17-38.

7. Rostami S, Sheikh AF, Shoja S, Farahani A, Tabatabaiefar MA, Jolodar A, Sheikhi R. Investigating of four main carbapenem-resistance mechanisms in high-level carbapenem resistant Pseudomonas aeruginosa isolated from burn patients. Journal of the Chinese Medical Association. 2018;81(2):127-32.

8. Amin NE, Giske CG, Jalal S, Keijser B, Kronvall G, Wretlind B. Carbapenem resistance mechanisms in Pseudomonas aeruginosa: alterations of porin OprD and efflux proteins do not fully explain resistance patterns observed in clinical isolates. Apmis. 2005;113(3):187-96.

9. Shen J, Pan Y, Fang Y. Role of the outer membrane protein OprD2 in carbapenem-resistance mechanisms of Pseudomonas aeruginosa. PloS one. 2015;10(10):e0139995.

10. Cowan S, Schirmer T, Rummel G, Steiert M, Ghosh R, Pauptit R, Jansonius J, Rosenbusch J. Crystal structures explain functional properties of two E. coli porins. Nature. 1992;358(6389):727.

11. Gutiérrez O, Juan C, Cercenado E, Navarro F, Bouza E, Coll P, Pérez J, Oliver A. Molecular epidemiology and mechanisms of carbapenem resistance in Pseudomonas aeruginosa isolates from Spanish hospitals. Antimicrob Agents Chemother. 2007;51(12):4329-35.

12. Lynch M, Drusano G, Mobley H. Emergence of resistance to imipenem in Pseudomonas aeruginosa. Antimicrob Agents Chemother. 1987;31(12):1892-6.

13. Huang $H$, Jeanteur D, Pattus F, Hancock RE. Membrane topology and site-specific mutagenesis of Pseudomonas aeruginosa porin OprD. Mol Microbiol. 1995 Jun;16(5):931-41. PubMed PMID: 7476190.

14. Dantas RCC, e Silva RT, Ferreira ML, Gonçalves IR, Araújo BF, de Campos PA, Royer S, da Fonseca Batistão DW, Gontijo-Filho PP, Ribas RM. Molecular epidemiological survey of bacteremia by multidrug resistant Pseudomonas aeruginosa: the relevance of intrinsic resistance mechanisms. PloS one. 2017;12(5):e0176774.

15. Gill MM, Usman J, Kaleem F, Hassan A, Khalid A, Anjum R, Fahim Q. Frequency and antibiogram of multi-drug resistant Pseudomonas aeruginosa. J Coll Physicians Surg Pak. 2011;21(9):531-4.

16. Hammami S, Ghozzi R, Burghoffer B, Arlet G, Redjeb S. Mechanisms of carbapenem resistance in non-metallo- $\beta$-lactamase-producing clinical isolates of Pseudomonas aeruginosa from a Tunisian hospital. Pathol Biol (Paris). 2009;57(7-8):530-5.

17. Kohanteb J, Dayaghi M, Motazedian M, Ghayumi M-A. Comparison of biotyping and antibiotyping of Pseudomonas aeruginosa isolated from patients with burn wound infection and nosocomial pneumonia in Shiraz. Iran Pakistan journal of biological sciences: PJBS. 2007;10(11):1817-22. 
18. Lei Y, Wang H, Sun Z, Shen Z. Susceptibility of 570 Pseudomonas aeruginosa strains to 11 antimicrobial agents and the mechanism of its resistance to fluoroquinolones. Zhonghua yi xue za zhi. 2003;83(5):403-7.

19. Levine C, Hiasa H, Marians KJ. DNA gyrase and topoisomerase IV: biochemical activities, physiological roles during chromosome replication, and drug sensitivities. Biochimica et Biophysica Acta (BBA)-Gene Structure and Expression. 1998;1400(1-3):29-43.

20. Sapino B, Mazzucato S, Solinas M, Gion M, Grandesso S. Comparison of different methods for determining beta-lactam susceptibility in Pseudomonas aeruginosa. Microbiologica-Quarterly Journal of Microbiological Sciences. 2012;35(4):491.

21. Zarei-Yazdeli M, Eslami G, Zandi H, Mousavi SM, Kosha H, Akhavan F, Kiani M. Relationship between antimicrobial resistance and class I integron in Pseudomonas aeruginosa isolated from clinical specimens in Yazd during 2012-2013. Feyz Journal of Kashan University of Medical Sciences. 2014;18(1).

22. Dubois V, Arpin C, Dupart V, Scavelli A, Coulange L, André C, Fischer I, Grobost F, Brochet J-P, Lagrange I. $\beta$-Lactam and aminoglycoside resistance rates and mechanisms among Pseudomonas aeruginosa in French general practice (community and private healthcare centres). Journal of antimicrobial chemotherapy. 2008;62(2):316-23.

23. Fournier D, Richardot C, Müller E, Robert-Nicoud M, Llanes C, Plésiat P, Jeannot K. Complexity of resistance mechanisms to imipenem in intensive care unit strains of Pseudomonas aeruginosa. $\mathrm{J}$ Antimicrob Chemother. 2013;68(8):1772-80.

24. Hirabayashi A, Kato D, Tomita Y, Iguchi M, Yamada K, Kouyama Y, Morioka H, Tetsuka N, Yagi T. Risk factors for and role of OprD protein in increasing minimal inhibitory concentrations of carbapenems in clinical isolates of Pseudomonas aeruginosa. Journal of medical microbiology. 2017;66(11):1562-72.

25. Sanbongi Y, Shimizu A, Suzuki T, Nagaso H, Ida T, Maebashi K, Gotoh N. Classification of OprD sequence and correlation with antimicrobial activity of carbapenem agents in Pseudomonas aeruginosa clinical isolates collected in Japan. Microbiol Immunol. 2009;53(7):361-7.

26. Wolter DJ, Hanson ND, Lister PD. Insertional inactivation of opr D in clinical isolates of Pseudomonas aeruginosa leading to carbapenem resistance. FEMS Microbiol Lett. 2004;236(1):137-43.

27. Sun Q, Ba Z, Wu G, Wang W, Lin S, Yang H. Insertion sequence ISRP10 inactivation of the oprD gene in imipenem-resistant Pseudomonas aeruginosa clinical isolates. Int $\mathrm{J}$ Antimicrob Agents. 2016;47(5):375-9.

28. Yan Y, Yao X, Li H, Zhou Z, Huang W, Stratton CW, Lu C-D, Tang Y-W. A novel oprD-mutated Pseudomonas aeruginosa strain in relation to a nosocomial respiratory infection outbreak in an intensive care unit. Journal of clinical microbiology. 2014:JCM. 02782-14.

29. Chalhoub H, Sáenz Y, Rodriguez-Villalobos H, Denis O, Kahl BC, Tulkens PM, Van Bambeke F. Highlevel resistance to meropenem in clinical isolates of Pseudomonas aeruginosa in the absence of 
carbapenemases: role of active efflux and porin alterations. Int $\mathrm{J}$ Antimicrob Agents. 2016;48(6):740-3.

\section{Tables}

Table 1- frequency of antibiotic resistance patterns in $P$. aeruginosa isolated from clinical samples

\begin{tabular}{|c|c|c|c|}
\hline Antibiotic & $\begin{array}{l}\text { Sensitive } \\
\text { No. (\%) }\end{array}$ & $\begin{array}{l}\text { Semi Sensitive } \\
\text { No. (\%) }\end{array}$ & $\begin{array}{l}\text { Resistant } \\
\text { No. (\%) }\end{array}$ \\
\hline Imipenem $(10 \mu \mathrm{g})$ & $44(48.9)$ & $2(2.2)$ & $44(48.9)$ \\
\hline Meropenem $(10 \mu \mathrm{g})$ & $38(42.2)$ & $1(1)$ & $51(56.6)$ \\
\hline Ertapenem $(10 \mu \mathrm{g})$ & $29(32.2)$ & $14(15.3)$ & $47(52 / 5)$ \\
\hline Ciprofloxacin $(5 \mu \mathrm{g})$ & $46(51.1)$ & $4(4.4)$ & $40(44.4)$ \\
\hline Ceftazidime $(30 \mu \mathrm{g})$ & $32(35.6)$ & $13(14)$ & $45(50)$ \\
\hline Cefepime $(30 \mu \mathrm{g})$ & $40(44.4)$ & $2(2.2)$ & $48(53.3)$ \\
\hline Ceftriaxone $(30 \mu \mathrm{g})$ & $26(28.9)$ & 17(18.9) & $48(53.3)$ \\
\hline Gentamicin $(10 \mu \mathrm{g})$ & $38(42.2)$ & $7(7.8)$ & $45(50)$ \\
\hline Tobramycin $(10 \mu \mathrm{g})$ & $37(41.1)$ & $8(8.8)$ & $45(50)$ \\
\hline
\end{tabular}

Table 2: The results of MIC for imipenem by an E. test

\begin{tabular}{|ll|}
\hline Resistant & $70(77.7 \%)$ \\
$\mathrm{MIC} \geq 16$ & \\
\hline Sensitive & $20(22.2 \%)$ \\
$\mathrm{MIC} \leq 4$ & \\
\hline
\end{tabular}

Table 3. The relation between mutation and MIC

\begin{tabular}{|llll|}
\hline \multirow{2}{*}{ E-test } & \multicolumn{2}{l}{ Mutation } & \multicolumn{1}{c|}{ Total } \\
\cline { 2 - 3 } & Yes & No & \\
\hline Resistant & $25(86.2 \%)$ & $0(0 \%)$ & $25(86.2 \%)$ \\
\hline Sensitive & $0(0 \%)$ & $4(13.7 \%)$ & $4(13.7 \%)$ \\
\hline Total & $25(86.2 \%)$ & $4(13.7 \%)$ & $29(100 \%)$ \\
\hline
\end{tabular}

Table 4. The results of the sequencing of upstream region of oprD gene and promoter 


\begin{tabular}{|c|c|c|}
\hline NO. of isolate & Description of mutation & Resistant/sensitive \\
\hline \multirow[t]{7}{*}{115} & $A \rightarrow G$ base substitution at $n t-30$ & $\mathrm{R}$ \\
\hline & $\begin{array}{l}T \rightarrow C \text { base substitution at nt } \\
-297\end{array}$ & \\
\hline & $\begin{array}{l}\mathrm{G} \rightarrow \mathrm{T} \text { base substitution at } \mathrm{nt} \\
-348\end{array}$ & \\
\hline & $\begin{array}{l}\begin{array}{l}C \rightarrow T \text { base substitution at } n t \\
-300\end{array} \\
\text {. }\end{array}$ & \\
\hline & $\begin{array}{l}A \rightarrow G \text { base substitution at } n t \\
-309\end{array}$ & \\
\hline & $\begin{array}{l}\mathrm{A} \rightarrow \mathrm{T} \text { base substitution at } \mathrm{nt} \\
-384\end{array}$ & \\
\hline & $\begin{array}{l}\mathrm{C} \rightarrow \mathrm{T} \text { base substitution at } \mathrm{nt} \\
-417\end{array}$ & \\
\hline \multirow[t]{2}{*}{18} & $\begin{array}{l}\mathrm{G} \rightarrow \mathrm{A} \text { base substitution at } \mathrm{nt} \\
-302\end{array}$ & $\mathrm{R}$ \\
\hline & $\begin{array}{l}G \rightarrow A \text { base substitution at } n t \\
-272\end{array}$ & \\
\hline \multirow[t]{2}{*}{125} & $\begin{array}{l}A \rightarrow C \text { base substitution at } n t \\
-273\end{array}$ & $\mathrm{R}$ \\
\hline & $\begin{array}{l}G \rightarrow C \text { base substitution at } n t \\
-120\end{array}$ & \\
\hline 49 & $\begin{array}{l}G \rightarrow T \text { base substitution at } n t \\
-252\end{array}$ & $\mathrm{R}$ \\
\hline $57,58,16,55,10$ & $\mathrm{~T} \rightarrow \mathrm{C}$ base substitution at $\mathrm{nt}-89$ & $\mathrm{R}$ \\
\hline \multirow[t]{2}{*}{$31,53,78,72,68,126,125,91$} & $\begin{array}{l}\mathrm{C} \rightarrow \mathrm{T} \text { base substitution at } \mathrm{nt} \\
-323\end{array}$ & $\mathrm{R}$ \\
\hline & $\begin{array}{l}C \rightarrow T \text { base substitution at nt } \\
-179\end{array}$ & \\
\hline \multirow[t]{5}{*}{$200,202,203,31,53,68,80,115,125,126,91,85$} & $\begin{array}{l}A \rightarrow G \text { base substitution at nt } \\
-594\end{array}$ & $\mathrm{R}$ \\
\hline & $\begin{array}{l}A \rightarrow G \text { base substitution at } n t \\
-432\end{array}$ & \\
\hline & $\begin{array}{l}A \rightarrow G \text { base substitution at } n t \\
-426\end{array}$ & \\
\hline & $\begin{array}{l}C \rightarrow T \text { base substitution at } n t \\
-357\end{array}$ & \\
\hline & $\begin{array}{l}\mathrm{C} \rightarrow \mathrm{T} \text { base substitution at } \mathrm{nt} \\
-285\end{array}$ & \\
\hline
\end{tabular}

Page 12/13 


\begin{tabular}{|c|c|c|}
\hline & $\begin{array}{l}G \rightarrow A \text { base substitution at } n t \\
-270\end{array}$ & \\
\hline & $\begin{array}{l}C \rightarrow G \text { base substitution at } n t \\
-216\end{array}$ & \\
\hline & $\begin{array}{l}\mathrm{G} \rightarrow \mathrm{A} \text { base substitution at nt- } \\
\text { - }\end{array}$ & \\
\hline & $\begin{array}{l}T \rightarrow A \text { base substitution at } n t \\
-144\end{array}$ & \\
\hline 7 & $\begin{array}{l}\text { Insertion of } 3 \mathrm{bp}(\mathrm{TCG}) \text { at nt } \\
-422,-423,-424\end{array}$ & $\mathrm{R}$ \\
\hline $48,49,17,18,122,203$ & $\begin{array}{l}G \rightarrow A \text { base substitution at nt } \\
-256\end{array}$ & $\mathrm{R}$ \\
\hline $17,49,55,10,122$ & Insertion of $1 \mathrm{bp}(\mathrm{C})$ at nt -420 & $\mathrm{R}$ \\
\hline
\end{tabular}

\section{Figures}

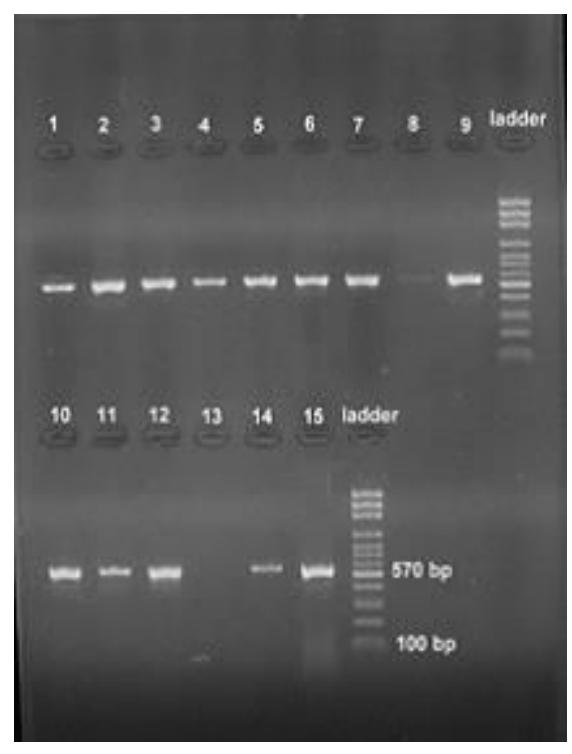

\section{Figure 1}

Agarose gel electrophoresis for amplification analysis of oprD Gene. Lane 1-12,14,15: oprD PCR result, lane 13: negative control, DNA ladder: 50bp. 